\title{
POLÍTICA PÚBLICA DE REFORMA AGRÁRIA: UM ESTUDO DE CASO NO RN NA PERSPECTIVA DA FUNÇÃO SOCIAL DA TERRA
}

\author{
F. F. SILVA, M. F. F. S. TACCONI \\ marli.tacconi@ifrn.edu.br
}

\section{RESUMO}

Este trabalho tem como objetivo avaliar se a função social da terra na política pública da reforma agrária é satisfatória nos projetos dos assentamentos Mulungu, Santa Maria, Pedro Ezequiel de Araújo, Bonfim e Progresso. De forma específica verificar o nível de utilização das terras concedidas, identificar o percentual de famílias que produzem e/ou utilizam o solo, identificar o Grau de Utilização das Terras (GUT) e analisar se as áreas concedidas tornam as famílias autossuficientes. A metodologia utilizada foi exploratória e descritiva, do tipo estudo de caso e com uma abordagem quantitativa. As análises dos resultados foram obtidas a partir da pesquisa de dados extraídos de formulários devidamente preenchidos por equipe técnica multidisciplinar, realizadas com os beneficiários da reforma agrária, bem como estudos documentais. Estes estudos apontam que os solos concedidos estão sendo subutilizados, além disso, foi constatado que o tamanho dos lotes é insuficiente para produzir renda de forma adequada a uma família, pois, com a pressão pela demanda da terra, o INCRA cria novos minifúndios, contrariando uma de suas premissas legais, uma vez que essa autarquia deveria contribuir para a extinção deste tido de fração rural. Conclui-se que são necessários estudos complementares que reforcem as informações levantadas neste trabalho e/ou que seja proposta uma nova fórmula de implementação da reforma agrária na região semiárida do Rio Grande do Norte.

Palavras-Chaves: Reforma agrária, Uso da terra, Grau de Utilização das Terras, Semiárido.

\begin{abstract}
This study aims to assess whether the social function of land in the public policy of land reform is satisfactory, the project settlements Mulungu, Santa Maria, Pedro Ezequiel de Araújo, Bonfim and Progresso. Specifically check the level of use of land granted, identify the percentage of families that produce and/or use the ground, identify the Degree of Use of Land (GUT) and analyze the areas granted make the self-sufficient families. The methodology used was exploratory and descriptive, the case study type and a quantitative approach. The analyzes of the results were obtained from the extracted forms data research duly completed by a multidisciplinary technical team, carried out with the beneficiaries of agrarian reform as well as documentary studies. These studies show that is being underutilized the granted land, in addition, it was found that the size of the lots are insufficient to produce income properly to a family, because with the pressure to demand land, INCRA creates new smallholdings, against one of its legal assumptions because such authority should contribute to the extinction of that had rural fraction. It is concluded that further studies are needed to strengthen the information gathered in this work and / or there is a proposed new land reform implementation of formula in the semiarid region of Rio Grande do Norte.
\end{abstract}

Keywords: Agrarian reform, Land use, Degree of Use of Land, Semiarid. 


\section{INTRODUÇÃO}

A questão agrária acompanha a história brasileira, marcando a base da organização da nossa sociedade, mas permanece distante de ser resolvida apesar dos diferentes movimentos sociais que aconteceram ao longo desse tempo. Essa questão é sempre complexa porque envolve as relações que se estabelecem dentro do movimento social, com o desenvolvimento de práticas emancipatórias e a construção de uma nova sociedade (FIGUEIREDO, 2009).

Além dessa complexidade, Com o novo cenário de cobrança da sociedade brasileira sobre a gestão pública, torna-se necessário que a utilização dos recursos financeiros seja realizada de forma eficiente, eficaz e efetiva. Assim, surge a necessidade de se avaliar as políticas públicas e os programas e projetos que são implementados com o objetivo de verificar de modo contínuo e amplo os indicadores de eficiência.

Nessa perspectiva, faz-se necessário também compreender como vivem as famílias que compõem os Projetos de Assentamentos (PA's) do estado do Rio Grande do Norte, implantados pelo Instituto Nacional de Colonização e Reforma Agrária (INCRA), com relação à produção, produtividade, utilização das áreas desapropriadas e condições de vida das famílias beneficiadas.

Devido à má distribuição de terras no Brasil, desde o século XVI, com a criação das capitanias hereditárias, há uma grande quantidade de mão de obra no campo, tendo em vista que, até meados do século XX, a maior parcela da população brasileira vivia predominantemente no meio rural. Surge, então, a necessidade de que haja uma melhor distribuição das terras, considerando-se, para tanto, uma melhor utilização deste recurso natural, melhor aproveitamento da mão de obra existente, gerando empregos no campo e evitando o êxodo rural e, consequentemente, uma melhor ocupação do território brasileiro (CARVALHO, 2015).

Segundo o Estatuto da Terra (Lei no 4.504/1964), a reforma agrária foi concebida com a ideia de que a terra cumprisse sua função social e econômica, noção que é confirmada pela Constituição Federal de 1988, a qual, de modo resumido, conceitua a terra como meio para a produção de alimentos e geração de empregos no campo. Todavia, para estímulo a esta função, a terra deverá ser utilizada de forma racional.

Com o objetivo de identificar como ocorre a racionalidade no uso da terra e quais os fatores que implicam no sucesso ou insucesso do seu uso, a Lei n ${ }^{\circ} 8.629$, de 25 de fevereiro de 1993, em seu art. $6^{\circ}$, traz o seguinte texto:

Art. $6^{\circ}$ Considera-se propriedade produtiva aquela que, explorada econômica e racionalmente, atinge, simultaneamente, graus de utilização da terra e de eficiência na exploração, segundo indices fixados pelo órgão federal competente.

$\int 1^{\circ} \mathrm{O}$ grau de utilização da terra, para efeito do caput deste artigo, deverá ser igual on superior a 80\% (oitenta por cento), calculado pela relação percentual entre a área efetivamente utilizada e a área aproveitável total do imóvel (BRASIL, 1993).

Este trecho traz uma síntese de um dos principais indicadores para que seja realizada a desapropriação dos imóveis rurais para fins de reforma agrária no Brasil, que é o Grau de Utilização da Terra (GUT).

Nessa perspectiva é importante desenvolver diversos processos investigativos que promovam a compreensão sobre a qualidade de vida das famílias assentadas e o uso racional do solo por parte dessas famílias, para que se possa identificar se a utilização dos recursos públicos está repercutindo no alcance da boa qualidade de vida desses grupos familiares e, em contrapartida, na geração de renda, emprego e produção de alimentos para a sociedade. 
Como a demanda é grande em relação à disponibilidade de lotes disponíveis para as famílias interessadas em participar da reforma agrária, realiza-se um processo de seleção das famílias para comporem tais áreas, de acordo com critérios definidos pela Norma de Execução SD/INCRA no 45 , de 25 de agosto de 2005, quando da implantação dos Projetos de Assentamentos.

O problema é que não se sabe, ao darem a concessão de uso das terras, se essas realmente serão exploradas de forma racional e economicamente viável, de modo que venham a produzir subsídios para o sustento das famílias que lá se instalam e trazer benefícios ao país com o aumento da taxa de ocupação da mão de obra ativa, o aumento do emprego rural e da oferta de produtos agrícolas.

Assegurar que os assentamentos tenham uma verdadeira viabilidade econômica é uma questão importante e que implica em uma política de localização dos projetos que favoreça as áreas mais próximas dos centros urbanos, em detrimento de áreas afastadas com pouca infraestrutura, reduzindo dessa forma os danos ambientais dos assentamentos (LE TOURNEAU; BURSZTYN, 2010).

Compreender a racionalidade do uso da terra é importante para que a política pública da reforma agrária possa atender aos anseios do público beneficiário e verificar a eficiência dos gastos públicos com essa política, levando-se em consideração os benefícios que poderá proporcionar à população em geral.

Com base no exposto, a presente pesquisa focou em alguns assentamentos na região semiárida do estado do Rio Grande do Norte, mais precisamente, nos municípios de Ipanguaçu (PA Santa Maria e Pedro Ezequiel de Araújo), Afonso Bezerra (PA Progresso), Angicos (PA Bonfim) e Pendências (PA Mulungu). Esses municípios se localizam entre as mesorregiões Oeste e Central potiguar.

Tendo em vista a eficiência com os gastos públicos referentes à aquisição de imóveis rurais no país, para identificar a real necessidade por terras para o Plano Nacional de Reforma Agrária (PNRA), surge então a seguinte indagação: a função social da terra, na política pública da reforma agrária, é satisfatória nos projetos de assentamentos? Sendo assim, o objetivo geral deste artigo é avaliar se a função social da terra, na política pública da reforma agrária, é satisfatória nos projetos de assentamentos de Mulungu, Santa Maria, Pedro Ezequiel de Araújo, Bonfim e Progresso. De forma específica, espera-se verificar o nível de utilização das terras concedidas; identificar o percentual de famílias que produzem e/ou utilizam o solo; identificar o Grau de Utilização das Terras (GUT); e analisar se as áreas concedidas tornam as famílias autossuficientes.

\section{POLÍTICA PÚBLICA DE REFORMA AGRÁRIA}

A política pública para atendimento da reforma agrária no Brasil surge formalmente através do Estatuto da Terra, através da Lei 4.504, de 30 de novembro de 1964. Depois dessa, diversas foram as leis, planos, programas, normativos e órgãos que trataram e tratam da matéria. Entre esses planos, pode-se citar o Plano Nacional de Reforma Agrária (PNRA), lançado em outubro de 1985, que foi criado através do Decreto $\mathrm{n}^{\circ} 91.766$ e, mais tarde, a fim de aperfeiçoar a reforma agrária, foi lançado, em novembro de 2003, o Plano Nacional de Reforma Agrária II, que tem o objetivo de tornar-se mais transparente no que tange aos gastos públicos e mais eficiente.

A necessidade de incentivar a exploração racional da terra é uma constatação bastante antiga. Em 1946, tornou-se imperativo constitucional "promover a justa distribuição da propriedade com igual oportunidade para todos". Em 1962, o Brasil subscreveu a "Carta de Punta del Este", reconbecendo expressamente a necessidade de realizar em seu território a Reforma Agrária (BRASIL, 1985). 
Diversos foram os fatores de pressão social para que houvesse a institucionalização da reforma agrária no país, a qual surge da necessidade de distribuição de terras para que o solo brasileiro possa atender a sua função social.

$A$ esse respeito, o Estatuto da Terra (art. $2^{\circ}, \int 1^{\circ}$ ) explicita que a propriedade rural desempenha integralmente a sua função social quando, simultaneamente: a) favorece o bemestar dos proprietários e dos trabalhadores que nela labutam, assim como de suas familias; b) mantém niveis satisfatórios de produtividade; c) assegura a conservação dos recursos naturais; d) observa as disposições legais que regulam as justas relações de trabalho entre os que a possuem e a cultiva (BRASIL, 1985).

As questões referentes à má distribuição de terras no Brasil datam de 1534, com a instituição das capitanias hereditárias que dividiram o território brasileiro, naquela época, em 15 faixas, pelo então Rei de Portugal D. João III, que soube do achado dos espanhóis em minérios valiosos no continente americano e queriam avançar na colonização do território para evitar ou diminuir as invasões estrangeiras (FREITAS, 2015).

Os capitães donatários recebiam do Rei de Portugal a Carta de Doação e o Foral da Capitania Hereditária. O primeiro documento servia para que cada capitão pudesse ocupar as terras sem que as pudessem vender ou repassar, sendo o repasse possível apenas aos seus descendentes. $\mathrm{O}$ segundo documento era um conjunto de direitos e deveres que os capitães deveriam seguir e/ou realizar junto a cada capitania.

Já o Foral determinava o conjunto especifico de direitos e obrigações que o capitão donatário teria em suas mãos. Ele poderia fundar vilas, doar sesmarias (lotes de terra não cultivados), exercer funçōes judiciárias e militares, cobrar tributos e realizar a escravização de um número fixo de indígenas. Com relação às atividades econômicas, ele poderia ter uma parte dos lucros, desde que isso não ferisse os direitos de arrecadação da Coroa Portuguesa (SOUSA, 2015).

Nesse contexto, através das sesmarias doadas pelos capitães donatários, iniciaram-se as primeiras propriedades brasileiras, entre elas, as rurais.

A questão inicial era ocupar as terras, que eram bem extensas e havia pouca estrutura ao longo de todo o território, fato que dificultava a sua colonização. Com o passar dos séculos, a imigração, a expansão das fazendas produtoras de cana-de-açúcar, tabaco, cacau, algodão, café, a pecuária bovina, a extração mineral, o tráfico de escravos, assim como sua abolição e muitos outros fatores fizeram com que houvesse concorrência no uso e na ocupação das terras, formando uma mão de obra ociosa no campo por falta da distribuição adequada destas áreas (RIBEIRO, 1995).

Havendo, portanto, a necessidade de atender aos anseios da população que precisava de terra para trabalhar, os governos brasileiros tentaram amenizar as pressões do campo a fim de: diminuir o êxodo rural de uma mão de obra de pouca valia nos centros urbanos, o que contribuía para o aumento desordenado dos principais centros; aumentar a oferta de emprego e alimento; contribuir com a melhoria da renda e das condições de vida da população de forma geral, tendo em vista que os aspectos negativos ou positivos no campo afetavam a vida da população urbana também (ALVES, 2006). Surge, então, a Lei 4.504, o Estatuto da Terra, que cria o marco legal para a instituição da reforma agrária no país. 


\section{INSTRUMENTOS E REGRAS PARA A REFORMA AGRÁRIA}

Diversos foram os elos legais da política pública do Plano Nacional de Reforma Agrária (PNRA), os quais estão descritos a seguir.

\section{Estatuto da Terra de 1964}

Este é o marco legal que trata do uso da terra e sua função social, a Lei 4.504, de 30 de novembro de 1964, também conhecida como Estatuto da Terra, através da qual a reforma agrária passa a tornar-se viável, sendo o primeiro passo de muitos que foram percorridos até os dias atuais, de forma legalizada, no Brasil.

Mesmo o país estando sob o regime militar, devido às pressões marcadas pelas lutas campesinas pelo direito ao uso da terra, o Estatuto da Terra foi o marco legal que criou a possibilidade de redistribuição da terra baseada no seu uso e produtividade, possibilitando, assim, que trabalhadores que não possuíssem os meios de comprar sua propriedade pudessem, através do apoio do governo, ter acesso a este meio de produção de alimento, emprego e renda.

Todas as demais leis e normativos que serão mencionados a seguir terão como alicerce a Lei 4.504/1964. A finalidade desses instrumentos é normatizar ou regulamentar algo que não foi possível através da lei de 1964.

\section{Lei $\mathrm{n}^{\circ} 5.868 / 1972$}

O INCRA promove a formação de minifúndios embasados em uma outra forma de divisão do imóvel rural, concebida pela Lei 5.868/1972, que traz em seu bojo a definição de fração mínima de parcelamento.

Art. $8^{\circ}$ Para fins de transmissão, a qualquer título, na forma do Art. 65 da Lei número 4.504, de 30 de novembro de 1964, nenbum imóvel rural poderá ser desmembrado ou dividido em área de tamanho inferior à do módulo calculado para o imóvel ou da fração minima de parcelamento fixado no $\int 1^{\circ}$ deste artigo, prevalecendo a de menor área.

$\int 1^{\circ}$ A fração minima de parcelamento será:

a) o módulo correspondente à exploração hortigranjeira das respectivas zonas típicas, para os municipios das capitais dos estados;

b) o módulo correspondente às culturas permanentes para os demais municípios situados nas zonas tipicas $A, B$ e $C$;

c) o módulo correspondente à pecuária para os demais municípios situados na zona tipica D (BRASIL, 1972).

Para a compreensão do que são as zonas típicas A, B, C e D, referidas no item "b" e "c" do trecho citado acima, eis as devidas definições retiradas da Instrução Especial/INCRA/No $05-a$, de 06 de junho de 1973:

a) Zona Típica "A", englobando zonas homogêneas compotencial demográfico médio superior a 100.000 (cem mil) babitantes/ quilometro;

b) Zona Típica "B”, englobando zonas homogêneas com potencial demográfico médio entre 60.000 (sessenta mil) e 100.000 (cem mil) babitantes/quilômetro;

c) Zona Típica " $C$ ", englobando zonas homogêneas com potencial demográfico médio entre 30.000 (trinta mil) e 60.000 (sessenta mil) habitantes/quilômetro; e 
d) Zona Típica 'D", englobando as demais zonas homogêneas (INCRA, 1973)

Deste modo, uma breve constatação torna-se possível: nos casos em que haja uma maior densidade demográfica, há uma predisposição para que sejam desmembradas ou loteadas áreas menores que o módulo fiscal. Este desmembramento, é dado pela fração mínima de parcelamento, que também é um dado definido de acordo com cada município, com base nas informações da Instrução Especial.

Com base nessa legislação específica, o INCRA tenta minimizar a demanda por terra pelos acampados ainda "sem terra". Porém, é importante tentar compreender se esta forma de atendimento do plano não prejudica seus beneficiários, tendo em vista que o módulo fiscal não foi ou não está sendo atendido, podendo interferir nas condições mínimas de viabilidade econômica. Isso pode ser verificado pela característica da região, visto que, segundo o Instituto Nacional do Semiárido (INSA), o estado do Rio Grande do Norte possui 92,97\% de sua área em região semiárida e historicamente sofre com secas rotineiras, que diminuem a possibilidade de produção agropecuária, somada à deficiência hídrica que impossibilita ou dificulta a produção por meio de técnicas de irrigação (INSA, 2015).

\section{Instrução Especial Incra no 20 , de 28 de maio de 1980}

Esta instrução trata de definir o tamanho do módulo fiscal em hectares(ha) para cada município do Brasil. É também relevante, antes de se verificar a correta distribuição de terras realizadas pelo INCRA aos beneficiários do PNRA, entender um pouco sobre como são conceituados os imóveis rurais quanto ao seu tamanho, neste caso, os módulos rurais e fiscais. Segundo o Estatuto da Terra, em seu art. $4^{\circ}$, propriedade rural e módulo rural são:

\section{II - "Propriedade Familiar", o imóvel rural que, direta e pessoalmente explorado pelo agricultor e sua familia, thes absorva toda a força de trabalho, garantindo-lhes a subsistência e o progresso social e econômico, com área máxima fixada para cada região e tipo de exploraşão, e eventualmente trabalhado com a ajuda de terceiros; \\ III - "Módulo Rural", a área fixada nos termos do inciso anterior (BRASIL, 1964).}

Outro meio de diferenciação entre os conceitos dos módulos está disponível no site do Serviço Nacional de Aprendizagem Rural - SENAR, como podem ser observados no quadro 1.

\section{Quadro 1 - Módulo Rural X Módulo Fiscal}

\begin{tabular}{|c|c|c|}
\hline & MÓDULO RURAL & MÓDULO FISCAL \\
\hline Finalidade & Determinar o enquadramento sindical rural & $\begin{array}{l}\text { Determinar a classificação dos imóveis rurais } \\
\text { em minifúndio, pequena, média e grande } \\
\text { propriedade }\end{array}$ \\
\hline Como é obtido & $\begin{array}{l}\text { O número de módulos rurais do imóvel é obtido } \\
\text { pelo somatório do número de módulos calculado } \\
\text { para cada tipo de exploração mais o número de } \\
\text { módulos calculado para a área agricultável mas não } \\
\text { explorada do imóvel }\end{array}$ & $\begin{array}{l}\text { O número de módulos fiscais é obtido } \\
\text { dividindo-se a área total do imóvel rural pelo } \\
\text { módulo fiscal do municipio }\end{array}$ \\
\hline Onde é encontrado & $\begin{array}{l}\text { No certificado de cadastro de imóvel rural emitido } \\
\text { pelo INCRA com base em dados fornecidos pelo } \\
\text { produtor rural na declaraçăo cadastral }\end{array}$ & $\begin{array}{l}\text { No certificado de cadastro de in } \\
\text { emitido pelo INCRA }\end{array}$ \\
\hline
\end{tabular}

Fonte: FAESC (2015). 
Para o INCRA, módulo fiscal pode ser definido da seguinte maneira:

O módulo fiscal representa uma unidade de medida instituida pelo INCRA (Instituto Nacional de Colonização e Reforma Agrária) para indicação da extensão minima das propriedades rurais consideradas áreas produtivas economicamente viáveis, o que depende do município em que cada uma está localizada (LANDAU et al., 2012, p. 5).

Portanto, o módulo fiscal tem o princípio de ser economicamente viável, mas isso varia de acordo com os municípios devido aos mais diversos fatores, como: aspectos climáticos, relevo, cultura local de produção, solo, condições locais sobre a comercialização agrícola, tais como logística, proximidade do mercado consumidor, organização dos produtores, entre outros.

Como o tamanho depende principalmente da disponibilidade de condições de produção, dinâmica de mercado, infraestrutura instalada, disponibilidade tecnológica e de aspectos naturais, como água e solo, municípios com maior acesso a essas condições demandam o uso de uma área menor para a obtenção de rentabilidade a partir das atividades ali desenvolvidas, apresentando tamanho do módulo fiscal menor. Já municípios com maior carência dessas condições apresentam módulos fiscais de maior dimensão (LANDAU et. al., 2012, p. 15).

Tendo em vista a grande diversidade dos fatores antes elencadas e das características diversas é possível compreender a variação do valor dos módulos fiscais nos municípios brasileiros. Os módulos fiscais foram instituídos pela Lei no 6.746, de 10 de dezembro de 1979, cujos hectares variam de 05 a 110 ha, o que ficou estabelecido pela Instrução Especial nº 20, de 1980.

No entanto, é relevante perceber que se trata de uma legislação relativamente antiga, por isso, uma nova foi elaborada e trata da convenção do módulo fiscal para os municípios que foram posteriormente criados. Essa nova legislação foi definida através das Instruções Especiais no 541, de 1997 (INCRA, 1997), e no 3, de 2005 (INCRA, 2005), para municípios instalados em 1997 e 2005, respectivamente. Vale salientar que as modificações trazidas nesse novo instrumento legal só se referem aos novos municípios, não trazendo modificações para os municípios que já haviam sido convencionados na Instrução Especial $\mathrm{n}^{\mathrm{o}} 20$.

A questão da extinção dos minifúndios, como descreve o Estatuto da Terra, tem fundamento na viabilidade econômica do imóvel. Neste sentido, Neto (1997) traz a seguinte colocação: “O minifúndio não atende ao princípio da função social da terra por não ter condições de consumir a força de trabalho familiar. Portanto, não garante a subsistência e nem o progresso do agricultor e de sua família. É tão nocivo quanto o latifúndio" (NETO, 1997, p. 55). Com a quantidade inadequada de terra para a produção, o agricultor irá depender sempre de outras formas de renda para manter a sustentabilidade de sua família, tendo em vista que o imóvel a ele concedido não possui condições suficientes de promover produção e, consequentemente, de gerar renda.

\section{Lei $n^{\circ} 8.629 / 1993$}

A classificação fundiária brasileira é dada a partir do módulo fiscal através da Instrução Especial no 20, de 1980, em relação a sua extensão. Com respeito ao tamanho das propriedades rurais, foi instituído, a partir da Lei $\mathrm{n}^{\circ}$ 8.629, de 25 de fevereiro de 1993, em seu art. $4^{\circ}$, que as propriedades fossem classificadas segundo seu tamanho em relação ao número de módulos, como:

- minifúndios: com tamanho de até um módulo fiscal;

- pequenas propriedades: com área entre um e quatro módulos fiscais;

- médias propriedades: com dimensão superior a quatro até 15 módulos fiscais e

- grandes propriedades: com área maior do que 15 módulos fiscais (LANDAU et. al., 2015, p. 08) 
Essa Lei também traz os indicadores que definem atualmente os índices de uso e produtividade das propriedades rurais para que estas sejam consideradas produtivas e cumpram sua função social.

Neste cerne, a Lei $\mathrm{n}^{\circ}$ 8.629/1993 regulamenta como e qual propriedade pode ser desapropriada para fins de reforma agrária, após a Constituição de 1988, trazendo como conceito de imóvel rural o seguinte:

Art. $4^{\circ}$ Para os efeitos desta lei, conceituam-se:

I-Imóvel Rural - o prédio rústico de área contínua, qualquer que seja a sua localização, que se destine ou possa se destinar à exploração agricola, pecuária, extrativa vegetal, florestal ou agroindustrial (BRASIL, 1993).

Mais adiante no mesmo artigo em seu parágrafo único, a Lei ainda define qual o tamanho mínimo para que a propriedade possa ser desapropriada:

Parágrafo unico. São insuscetiveis de desapropriação para fins de reforma agrária a pequena e a média propriedade rural, desde que o seu proprietário não possua outra propriedade rural (BRASIL, 1993).

Logo adiante, em seu art. $6^{\circ}$, a Lei argumenta sobre qual o critério utilizado para a desapropriação de imóvel rural, a qual se baseia mais precisamente no Grau de Utilização da Terra (GUT) e no Grau de Eficiência na Exploração (GEE) de imóveis rurais brasileiros:

Art. $6^{\circ}$-Considera-se propriedadeprodutiva aquela que, explorada econômica e racionalmente, atinge, simultaneamente, graus de utilização da terra e de eficiência na exploração, segundo indices fixados pelo órgão federal competente.

$\int 1^{\circ} \mathrm{O}$ grau de utilização da terra, para efeito do caput deste artigo, deverá ser igual ou superior a 80\% (oitenta por cento), calculado pela relação percentual entre a área efetivamente utilizada e a área aproveitável total do imóvel.

$\int 2^{\circ} \mathrm{O}$ grau de eficiência na exploração da terra deverá ser igual ou superior a 100\% (cem por cento) (BRASIL, 1993).

Os índices de produtividade, referentes ao GUT citados no art. $6^{\circ}$ da Lei 8.629/1993, estão descritos e normatizados através da Instrução Normativa n ${ }^{\circ} 11$ do INCRA, de 04 de abril de 2003, que foi publicada no Diário Oficial da União no 74, de 16 de abril de 2003, seção 1, página 101. Tais índices serão levados em consideração no momento da avaliação do GUT dos projetos de assentamento objetos deste trabalho.

Também é fundamental citar que em seu art. $9^{\circ}$, essa Lei cita critérios que devem ser atendidos pela propriedade rural, a fim de se atingir sua função social que, em síntese, descreve sobre: os graus de utilização da terra; o respeito à legislação ambiental quanto ao uso racional dos recursos naturais; a não manutenção de trabalho escravo ou forma similar de não observância aos direitos dos trabalhadores; e, por fim, mas não menos importante, que a exploração da terra não prejudique o ambiente, favorecendo o bem-estar de quem viva ou trabalhe na propriedade, assim como da comunidade onde se localiza. Portanto, é importante ressaltar que a função social da terra não é só de produzir alimentos, mas também de propiciar um ambiente justo para todos que convivem e usufruem desse bem. 


\section{METODOLOGIA}

A pesquisa é de natureza aplicada, pois visa o conhecimento para diversas utilidades da área afim, como a avaliação de políticas públicas. Quanto à abordagem do problema, este estudo se apresenta de forma quantitativa, tendo em vista que serão expressos em números os resultados, o que irá gerar as análises a partir destes.

Quanto aos objetivos, esta pesquisa é delineada como exploratória e descritiva, uma vez que, como aponta Gil (1991), possui a finalidade de harmonizar maior intimidade com o problema a fim de deixálo mais evidente e de descrever as particularidades de certa população e/ou consignar relações entre as variáveis.

Para a obtenção dos dados, o procedimento utilizado foi a análise documental, com o uso das informações contidas nos formulários denominados Diagnósticos do Programa Brasil Sem Miséria, do Ministério do Desenvolvimento Social (MDS). Tais diagnósticos foram aplicados por equipes multidisciplinares de técnicos contratados junto ao INCRA para prestarem serviços de Assistência Técnica e Extensão Rural (ATER) e foram coletados no mês de julho de 2014.

A pesquisa foi fundamentada em alguns assentamentos na região semiárida do estado do Rio Grande do Norte, mais precisamente nos municípios de Ipanguaçu (PA Santa Maria e Pedro Ezequiel de Araújo), Afonso Bezerra (PA Progresso), Angicos (PA Bonfim) e Pendências (PA Mulungu), que são municípios que fazem parte das microrregiões do Vale do Açu e Angicos. É importante destacar que os municípios que compõem a pesquisa possuem os seguintes tamanhos dos módulos fiscais: Afonso Bezerra - 60 hectares; Alto do Rodrigues - 65 hectares; Angicos - 60 hectares; Ipanguaçu - 55 hectares; Pendências - 65 hectares. Porém, a fração mínima de parcelamento para estes municípios é de quatro hectares apenas (INCRA, 1980).

Para esta pesquisa foram coletadas informações de uma amostra relativa, tendo como média 30,86\% do número de famílias de todos os PA, conforme mostra a tabela 1.

Tabela 1-Quantitativos da amostra

\begin{tabular}{cccc}
\hline PA's & No de Famílias & Quant. da amostra & $\%$ \\
\hline Bonfim & 45 & 14 & 31,11 \\
\hline Mulungu & 32 & 10 & 31,25 \\
\hline Pedro Ezequiel & 528 & 160 & 30,30 \\
\hline Progresso & 80 & 25 & 31,25 \\
\hline Santa Maria & 204 & 62 & 30,39 \\
\hline TOTAL & 889 & 271 & 30,48 \\
\hline
\end{tabular}

Fonte: Elaborado pelos autores (2016).

Como se pode observar, a amostra média foi de 30,48\%, considerando-se todos os PA's nos quais foram realizadas a pesquisa, sendo o número mínimo de 30,30\% da população em cada PA.

O diagnóstico foi aplicado através da realização de entrevistas com as famílias assentadas feitas pelas equipes citadas, formadas por técnicos de diversas áreas, mais predominamente das ciências agrárias e sociais, que atuam nestes PA's através do Contrato CRT-RN 6.000/14 entre o Incra/RN/SR-19 e o Centro de Estudos e Assessoria Aplicados ao Desenvolvimento (CEAAD).

As informações foram coletadas de acordo com os formulários Diagnósticos do Programa Brasil Sem Miséria, que foram inseridos no Sistema Informatizado de Assistência Técnica e Extensão Rural (SIATER) do Ministério do Desenvolvimento Agrário (MDA) e são acessíveis a qualquer cidadão, necessitando apenas de um cadastro na plataforma do SIATER/MDA. 
Cabe ressaltar que foram objeto de investigação para esta pesquisa, dentre as muitas perguntas constantes no formulário, as informações sobre os itens 2, 10 e 11, que se referem respectivamente a: informações da família assentada; atividades extrativistas e comercialização; e produção e comercialização; além dos dados gerais do que é produzido nos PA’s e dados sobre a ocupação das áreas.

Outros levantamentos de dados foram realizados junto ao INCRA, assim, foram pesquisados os Laudos de Vistoria do Imóvel, a Portaria de Criação do Assentamento, o Auto de Imissão de Posse, Mapas Cartográficos e Relação de Beneficiários, documentos contidos nos autos dos processos de criação dos PA's, nos quais foram coletados dados como tamanho, distribuição, data de criação, número de beneficiários, entre outras informações que estão descritas nesta pesquisa.

\section{RESULTADOS DA PESQUISA}

As famílias que compõem a pesquisa já se encontram instaladas nos respectivos PA’s há mais de oito anos, possuem casas e receberam os créditos iniciais advindos do INCRA, cuja finalidade é fornecer condições mínimas ao início da produção nas áreas de assentamento.

Com relação à população dos PA's pesquisados, a amostragem compõe mais que 30\%, sendo a população composta por 889 famílias assentadas. A amostra realizada foi desenvolvida nos projetos de assentamentos Mulungu, Santa Maria, Pedro Ezequiel de Araújo, Bonfim e Progresso, perfazendo 271 famílias, valor que corresponde a 30,48\% do total de famílias assentadas nestes PA's. Quanto à força de trabalho de cada família, identificou-se uma média de 3,56 pessoas por família.

\section{Utilização das áreas concedidas nos PA's}

$\mathrm{Na}$ pesquisa, verificou-se que a utilização das áreas que as famílias detêm a concessão estão sendo subutilizadas, porque, do total de 4.576,68 hectares disponíveis para as 271 famílias, apenas 2.018,36 ha $(44,1 \%)$ estão sendo ocupados/utilizados por 112 famílias, de acordo com as informações levantadas nos formulários aplicados. Essas informações foram convergidas utilizando-se a Instrução Normativa n ${ }^{\circ} 11$, de 04 de abril de 2003, isso quando a área ocupada ainda não havia sido discriminada em hectares.

O dado global não separa quem usa de forma adequada a terra e quem não faz o uso apropriado. A tabela 2, a seguir, foi elaborada para identificar quem atualmente alcança os índices almejados para uma utilização satisfatória:

Tabela 2 - Uso dos solos pelos beneficiários

\begin{tabular}{crrrrr}
\hline \multicolumn{1}{c}{ USO DO SOLO } & $\begin{array}{c}\text { No de familias } \\
\text { que utiliza a } \\
\text { área } \\
\text { concedida }\end{array}$ & $\begin{array}{c}\% \text { das } \\
\text { familias }\end{array}$ & $\begin{array}{c}\text { Área } \\
\text { utilizada } \\
\text { (ha) }\end{array}$ & $\begin{array}{c}\text { \% da área } \\
\text { utilizada }\end{array}$ \\
\hline Uso acima de $100 \%$ & 28 & $10,33 \%$ & 1733,48 & $85,89 \%$ \\
\hline Uso entre $80 \%$ a $100 \%$ & 02 & $0,74 \%$ & 32,11 & $1,59 \%$ \\
\hline Uso abaixo dos $80 \%>0$ & 82 & $30,26 \%$ & 252,77 & $12,52 \%$ \\
\hline TOTAL & 112 & $41,33 \%$ & $2.018,36$ & $100,0 \%$ \\
\hline
\end{tabular}

Fonte: Elaborado pelos autores (2016). 
Como discutido anteriormente, a Lei $\mathrm{n}^{\circ} 8.629 / 1993$ traz em seu art. $6^{\circ}$, parágrafo primeiro, a informação de que pelo menos $80 \%$ da área útil do imóvel deve estar sendo explorada. Por isso, a tabela 2 foi elaborada para identificar quem utiliza abaixo de $80 \%$, de $80 \%$ a $100 \%$ e acima de $100 \%$ do solo.

Ao serem comparados os dados da tabela 2 com a informação sobre a ocupação da terra, parece bastante proporcional que $41,33 \%$ das famílias utilizem $44,1 \%$ da área concedida, se não fosse o fato de que apenas 10,33\% das famílias utilizam uma área maior do que a que lhes foi concedida, estas detêm o uso de 85,89\% da área total utilizada, que é de 2.018,36 ha, apresentando, assim, discrepâncias no seu uso. Dessa forma, das 271 famílias assentadas da amostra, apenas duas famílias fazem o uso apropriado das terras que lhes foram concedidas. O que representa menos de 1\% das famílias. Este dado faz emergir a necessidade de maiores discussões sobre o uso da terra nas políticas de reforma agrária brasileira.

\section{Identificando o percentual de famílias que produzem e/ou utilizam o solo}

As informações que foram coletadas sobre este item mostram um volume interessante de famílias que não ocupam racionalmente os lotes que lhes foram concedidos pelo INCRA. De acordo com o gráfico 1, pode-se observar o quanto é expressivo este volume.

\section{Gráfico 1 - Percentual das familias que utilizam o solo}

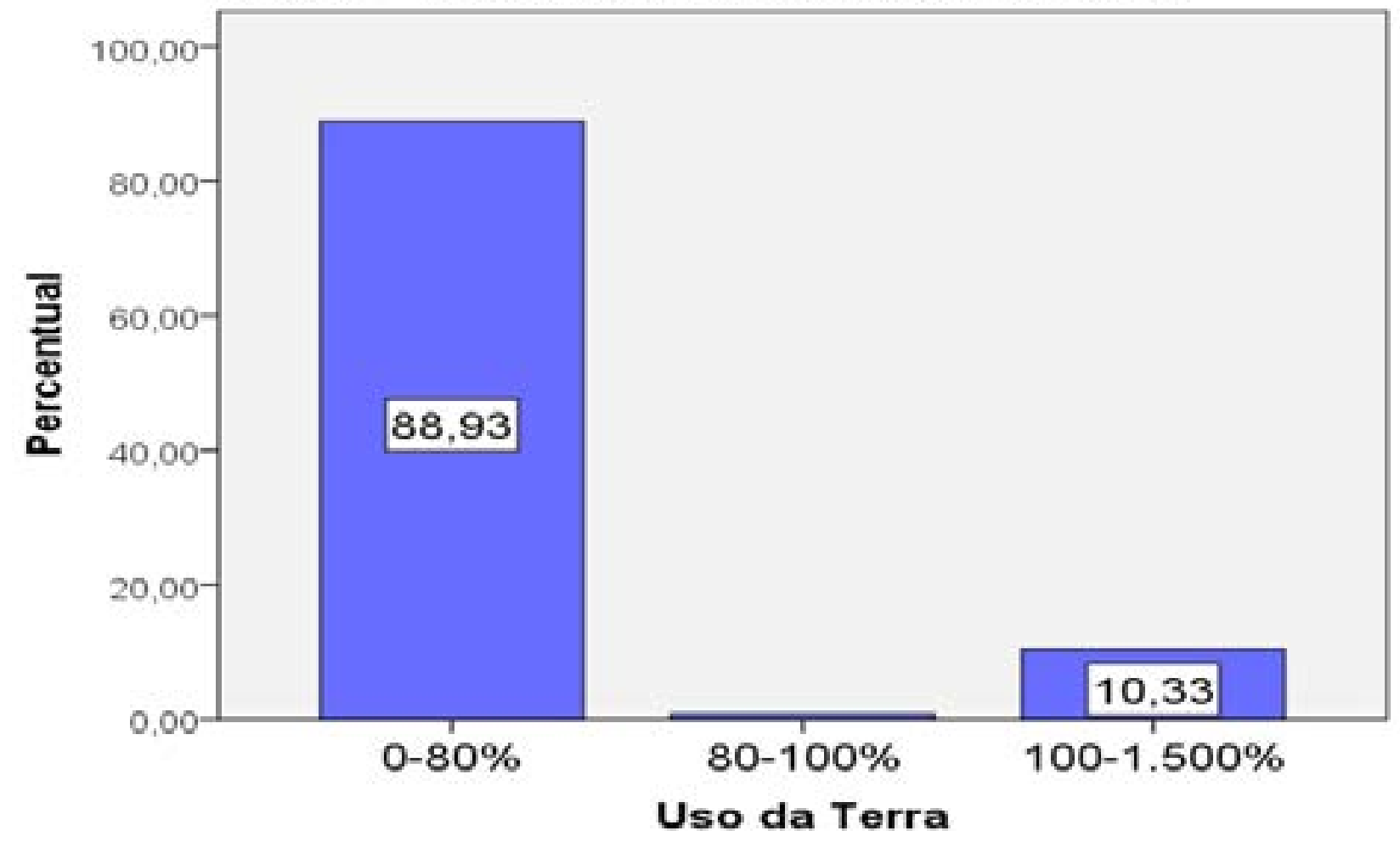

Fonte: Elaborado pelos autores (2016).

De acordo com os dados levantados e demonstrados no gráfico 1, constata-se que apenas $0,74 \%$ da amostra ocupa regularmente a sua área, em contrapartida, quase $89 \%$ da amostra não ocupa de forma racional os lotes, infringindo o art. $6^{\circ}, \$ 1^{\circ}$ da Lei $n^{\circ} 8.629 / 1993$. Um outro dado intrigante é que cerca de $10,33 \%$ da amostra é composta por famílias que ocupam mais do que os $100 \%$ da área a que lhes foram destinadas.

Isso ocorre principalmente quando se trata de criações extensivas de animais como bovinos, ovinos e caprinos, que são soltos nas áreas do assentamento e se alimentam em áreas que ainda não foram cercadas de lotes não ocupados. 


\section{Grau de utilização das áreas concedidas}

Quanto ao Grau de Utilização das Terras, este é um dos dados mais importantes analisados, pois é um dos principais elementos que fundamenta a desapropriação dos imóveis rurais para transformá-los em Projetos de Assentamentos. O GUT é fornecido através de leis e normativos específicos que, além de outros aspectos, também servem como referência/indicadores para se avaliar o quanto as propriedades rurais brasileiras e, neste caso, os PA’s pesquisados estão utilizando/ocupando suas áreas.

Portanto, observa-se que, para estas famílias (que utilizam $>100 \%$ ), é muito mais interessante que outras famílias não utilizem de fato suas áreas, o que lhes possibilita a expansão de suas criações. Uma forma mais detalhada de como ocorre a ocupação dos lotes pelas famílias pesquisadas pode ser observada na tabela 3 , a seguir.

\section{Tabela 3 - Quanto ao Grau de Utilização da Terra (GUT) por familia}

\begin{tabular}{|c|c|c|c|c|c|}
\hline Faixas do GUT & Absoluto & Percentual & $\begin{array}{l}\text { Número de } \\
\text { familias }\end{array}$ & GUT - detalhado & Percentual \\
\hline \multirow{9}{*}{$\begin{array}{l}\text { GRUPO QUE } \\
\text { UTIUZA DE } \\
0,0 \% \text { a } 80 \%\end{array}$} & \multirow{9}{*}{241} & \multirow{9}{*}{$88,93 \%$} & 159 & Não utilizam & $58,67 \%$ \\
\hline & & & 27 & $\begin{array}{l}\text { Utilizam até } 10 \% \text { da área } \\
\text { concedida }\end{array}$ & $9,96 \%$ \\
\hline & & & 28 & $\begin{array}{l}\text { Utilizam de } 10 \% \text { a } 20 \% \text { da } \\
\text { área concedida }\end{array}$ & $10,33 \%$ \\
\hline & & & 10 & $\begin{array}{l}\text { Utilizam de } 20 \% \text { a } 30 \% \text { da } \\
\text { área concedida }\end{array}$ & $3,69 \%$ \\
\hline & & & 10 & $\begin{array}{l}\text { Utilizam de } 30 \% \text { a } 40 \% \text { da } \\
\text { área concedida }\end{array}$ & $3,69 \%$ \\
\hline & & & 2 & $\begin{array}{l}\text { Utilizam de } 40 \% \text { a } 50 \% \text { da } \\
\text { área concedida }\end{array}$ & $0,74 \%$ \\
\hline & & & 2 & $\begin{array}{l}\text { Utilizam de } 50 \% \text { a } 60 \% \text { da } \\
\text { área concedida }\end{array}$ & $0,74 \%$ \\
\hline & & & 1 & $\begin{array}{l}\text { Utilizam de } 60 \% \text { a } 70 \% \text { da } \\
\text { área concedida }\end{array}$ & $0,37 \%$ \\
\hline & & & 2 & $\begin{array}{l}\text { Utilizam de } 70 \% \text { a } 80 \% \text { da } \\
\text { área concedida }\end{array}$ & $0,74 \%$ \\
\hline \multirow{2}{*}{$\begin{array}{l}\text { GRUPO QUE } \\
\text { UTILZA DE } \\
80 \% \text { A } 100 \%\end{array}$} & \multirow{2}{*}{2} & \multirow{2}{*}{$0,74 \%$} & 0 & $\begin{array}{l}\text { Utilizam de } 80 \% \text { a } 90 \% \text { da } \\
\text { área concedida }\end{array}$ & $0,00 \%$ \\
\hline & & & 2 & $\begin{array}{l}\text { Utilizam de } 90 \% \text { a } 100 \% \text { da } \\
\text { área concedida }\end{array}$ & $0,74 \%$ \\
\hline \multirow{6}{*}{$\begin{array}{l}\text { GRUPO QUE } \\
\text { UTILIZA DE } \\
100 \% \text { a } 1.500 \%\end{array}$} & \multirow[t]{6}{*}{28} & \multirow[t]{6}{*}{$10,33 \%$} & 11 & $\begin{array}{l}\text { Utilizam de } 100 \% \text { a } 200 \% \text { da } \\
\text { área concedida }\end{array}$ & $4,06 \%$ \\
\hline & & & 4 & $\begin{array}{l}\text { Utilizam de } 200 \% \text { a } 300 \% \text { da } \\
\text { área concedida }\end{array}$ & $1,48 \%$ \\
\hline & & & 2 & $\begin{array}{l}\text { Utilizam de } 300 \% \text { a } 400 \% \text { da } \\
\text { área concedida }\end{array}$ & $0,74 \%$ \\
\hline & & & 1 & $\begin{array}{l}\text { Utilizam de } 400 \% \text { a } 500 \% \text { da } \\
\text { área concedida }\end{array}$ & $0,37 \%$ \\
\hline & & & 9 & $\begin{array}{l}\text { Utilizam de } 500 \% \text { a } 1000 \% \text { da } \\
\text { área concedida }\end{array}$ & $3,32 \%$ \\
\hline & & & 1 & $\begin{array}{l}\text { Utilizam de } 1000 \% \text { a } 1500 \% \\
\text { da área concedida }\end{array}$ & $0,37 \%$ \\
\hline TOTAL & 271 & $100,00 \%$ & 271 & & $100,00 \%$ \\
\hline
\end{tabular}

Fonte: Elaborado pelos autores (2016) 
Os dados da tabela 3 são desdobramentos mais detalhados das informações contidas no gráfico 1, o qual permite-se realizar algumas análises. O dado de maior vulto na tabela 3 foi a constatação de que 159 famílias, 59\% da amostra, não produzem ou ocupam qualquer espaço que lhes tenha sido concedido com o objetivo da produção agropecuária, cuja finalidade é prover o sustento dessas famílias a partir da renda de produtos agrícolas.

As possíveis observações oriundas da análise dessas informações podem ocorrer por dois principais condicionantes:

a) A pesquisa pode não ter levantado dados fidedignos, pois, como se trata de declarações colhidas com os próprios assentados, sem que os mesmos necessitem comprovar a sua veracidade, há a possibilidade destas famílias, devido ao receio de perderem vantagens ou benefícios sociais, terem omitido informações que pudessem elevar seu nível de produção e renda por acharem que tais informações pudessem prejudicá-los;

b) A reforma agrária não está atendendo ao seu público-alvo. Neste caso, é possível que com a dificuldade de acesso às políticas públicas na busca por moradias, muitas das famílias ocupam e se beneficiam da reforma agrária pelo simples fato de terem acesso a uma "casa" nos projetos de assentamentos, além do acesso a crédito, sem que essas famílias tenham aptidão para a produção agrícola.

Nesses casos, como sugestão para futuras pesquisas, cabe um melhor levantamento sobre qual ou quais os motivos de maior relevância sustentam a problemática aqui apresentada e uma revisão sobre quais os rumos que serão dados a esta política de tamanha valia para a geração de emprego e renda na zona rural. E ainda, se for o caso, um enfoque na questão: por qual política pública a população anseia, haja vista que a distribuição de casas populares consome muito menos recursos públicos que a aquisição de terras, cada vez mais escassas e caras neste país.

\section{Grau de utilização das áreas concedidas}

Para a identificação da capacidade produtiva dos lotes distribuídos pela reforma agrária na região pesquisada, utilizou-se o tamanho das áreas e a sua capacidade de produção agropecuária.

A tabela 4 mostra que os lotes possuem áreas bastante limitadas, o que reduz a possibilidade de produção agropecuária suficiente para render divisas que tornem as famílias autossuficientes, principalmente por se tratar de regiões semiáridas.

Tabela 4 - Tamanho dos lotes em relaçăo aos módulos fiscais

\begin{tabular}{|c|c|c|c|c|c|c|}
\hline PA & $\begin{array}{c}\text { Familias } \\
\text { da } \\
\text { amostra }\end{array}$ & $\begin{array}{l}\text { Area dos } \\
\text { lotes da } \\
\text { amostra }\end{array}$ & $\begin{array}{c}\text { Áreo } \\
\text { média/lote }\end{array}$ & Município & $\begin{array}{c}\text { Módulo Fiscal } \\
\text { em ha }\end{array}$ & $\begin{array}{l}\text { \% Lote versus } \\
\text { Módulo Fiscal }\end{array}$ \\
\hline Bonfim & 14 & 189,20 & 13,51 & Angicos & 60 & $22,52 \%$ \\
\hline Mulungu & 10 & 160,36 & 16,04 & Pendências & 65 & $24,67 \%$ \\
\hline Pedro Ezequiel & 160 & $2.853,33$ & 17,83 & Ipanguaçu & 55 & $32,42 \%$ \\
\hline Progresso & 25 & 363,77 & 14,55 & $\begin{array}{l}\text { Afonso } \\
\text { Bezerra }\end{array}$ & 60 & $24,25 \%$ \\
\hline Santa Maria & 62 & $1.010,03$ & 16,29 & Ipanguaçu & 55 & $29,62 \%$ \\
\hline TOTAL & 271 & $4.576,68$ & 16,89 & & & \\
\hline
\end{tabular}

Fonte: Elaborado pelos autores (2016). 
Na tabela 4, observa-se a área média destinada às famílias de cada PA e a área dos lotes distribuídos pelo INCRA no estado do Rio Grande do Norte comparadas aos módulos fiscais de cada município nos quais os PA’s estão inseridos.

De acordo com os dados das áreas pesquisadas, os lotes dos beneficiários variam de 22,52\% a 32,42\% do tamanho de um módulo fiscal, ou seja, o órgão que tinha como obrigação extinguir os minifúndios do país, de acordo com o Estatuto da Terra, na realidade, cria novos.

Com relação à grande diferença entre o tamanho dos lotes e o módulo fiscal da região, há uma incongruência no sentido de que o mesmo órgão que possui a premissa de defender as informações técnicas que se baseiam na Instrução Normativa no $11 / 2003$, a qual norteia a produção média dos imóveis rurais, realize a distribuição de áreas muito aquém do que seria o mínimo necessário à sobrevivência das famílias beneficiadas. Logo, é pertinente o questionamento sobre qual seria o tamanho ideal dos lotes para que as famílias pudessem suprir suas necessidades e retirar de tal área o seu sustento.

Deve-se analisar, portanto, que a maioria das famílias não detêm conhecimentos necessários para responder a estas questões, e que, sem uma avaliação técnica, elas tenderão a produzir sem saber ao certo se irão gerar o suficiente para prover o seu sustento.

É importante que tais medidas sejam reavaliadas, pois as quantidades de terras que são distribuídas pela reforma agrária, em alguns casos, constatados nesta pesquisa, chega a $1 \frac{1}{4}$ de um módulo fiscal, ou seja, não possuem uma área mínima para que as famílias "beneficiadas" possam produzir o suficiente para a obtenção de uma renda digna.

A Instrução Normativa n ${ }^{\circ}$ 11/2003 apresenta, em uma de suas tabelas, informações técnicas que visam demonstrar a capacidade produtiva das áreas e a classificação das zonas pecuárias, o que pode ser visualizado na tabela 5 .

Tabela 5 - Dados da Instrução Normativa nำ 11/2003

\begin{tabular}{c|c}
\hline \multicolumn{2}{c}{ INDICES DE RENDIMENTOS MÍNIMOS PARA PECUÁRIA } \\
\hline ZONA PECUÁRIA & $\begin{array}{c}\text { ÍNDICE DE LOTAÇÃO } \\
\text { Unidades animais/ha }\end{array}$ \\
\hline 1 & 0,60 \\
\hline 2 & 0,46 \\
\hline 3 & 0,33 \\
\hline 4 & 0,16 \\
\hline 5 & 0,10 \\
\hline
\end{tabular}

Fonte: INCRA (2003).

Para uma melhor compreensão do que a zona pecuária representa na realidade dos PA’s pesquisados, a tabela 6 apresenta as informações das zonas pecuárias de cada município nos quais os PA's estão inseridos.

\begin{tabular}{|c|c|c|}
\hline Municleios & Zona Pecouínia & PA's: \\
\hline Afonse Beztera & 5 & Precetso \\
\hline Aneicos & 5 & Bontim \\
\hline ipareuacu & 4 & Sama Maria \\
\hline Iparcuacu Afenso Beterra e Ancicos. & 4 ou 5 & Pedro Eteouiel de Araligo \\
\hline fendincias & 4 & Molunes \\
\hline
\end{tabular}


É importante ressaltar que as áreas pesquisadas têm predominância como áreas de zona pecuária $\mathrm{n}^{\circ} 5$, uma vez que a variação tem base nas informações das áreas do município como um todo. Como os municípios de Ipanguaçu e Pendências possuem áreas banhadas pelo Rio Piranhas/Assu, as áreas totais desses municípios sofrem influência dos setores que margeiam o rio, portanto, produzem mais que o restante das outras áreas. Como nenhum outro dos PA's pesquisados possui área nesses setores privilegiados em termos de umidade, logo, conclui-se tal predominância.

Considerando-se as informações expostas nas tabelas anteriores, além das demais informações técnicas da Instrução Normativa n ${ }^{\circ} 11 / 2003$, é possível fazer um cálculo simples para identificar que com a média da área dos lotes que são concedidos aos beneficiários da reforma agrária nestes assentamentos, cada lote consegue ter sua plenitude de utilização com apenas duas matrizes bovinas, ou seja, duas vacas.

Cálculo:

Dados:

Área média dos lotes $=16,89 \mathrm{ha}$;

Zona pecuária $=5$, ou seja, cada hectare produz 0,1 Unidade Animal (U.A.)

Índice de Lotação, dada em U.A. de uma matriz bovina (vaca) $=0,83$

Então:

16,89 ha $x$ 0,1 U.A = 1,689 U.A.

1,689 U.A. / 0,83 = 2,03 matrizes bovinas em cada lote.

No que diz respeito à produção de bovinos, é difícil sustentar uma família com a renda produzida por apenas duas matrizes bovinas. Isso é preocupante, pois, no momento da distribuição das terras para as famílias assentadas, pela inexperiência de muitos dos chamados "sem terras" ou pela falta de conhecimento técnico produtivo, algumas famílias não conseguem perceber o quanto as áreas são pequenas para a produção agropecuária. De modo que os assentados procuram antes produzir e só depois dos resultados do seu trabalho, limitado por um lote pequeno, frustram-se por não terem conseguido a tão almejada sustentabilidade do ponto de vista econômico. O que gera um passivo de responsabilidade para o Estado por não ter resolvido o problema da geração de renda para estas famílias. Nessa mesma direção, Mourad (2010, p. 161) descreve que "os assentamentos atenuam o problema de acesso à terra, mas não, necessariamente, resolvem questões relativas à produção. Uma das reinvindicações dos movimentos sociais é que o Estado dê condições mínimas para o desenvolvimento da agricultura dos assentamentos".

\section{CONSIDERAÇÕES FINAIS}

Considerando-se o objetivo de avaliar se a função social da terra na política pública da reforma agrária é satisfatória nos projetos de assentamentos Mulungu, Santa Maria, Pedro Ezequiel de Araújo, Bonfim e Progresso, conclui-se que a política pública não atende a um grande número de famílias que ainda se encontram "sem-terra" neste país. Isso ocorre tanto nos acampamentos como para muitos dos agricultores que não conseguem uma área para produzir e prover seu sustento no meio rural. Por outro lado, os números confirmam que há um grande número de pessoas que foram beneficiadas, no entanto, não produzem ou não utilizam a área concedida de forma racional, fazendo com que a função social da terra nas áreas de assentamentos esteja aquém do esperado. 
Durante a pesquisa, foi possível perceber que boa parte do público beneficiário da reforma agrária não se configura como agricultores, visto que exercem outras profissões para o provimento da sua sustentabilidade e utilizam os assentamentos apenas como moradia. Tal informação sugere que a política de reforma agrária está sendo desviada para atender à necessidade ou deficiência de outra questão da política pública que seria a da habitação.

Os minifúndios criados pelo INCRA tendem a ser prejudiciais à sobrevivência e à sustentabilidade das famílias atendidas pelo PNRA, pois as famílias que dependem apenas da terra para produzir seu sustento, se forem utilizadas apenas as áreas que lhes foram destinadas, o lote tende a não ser suficiente para produzir a renda necessária ao suprimento das famílias, tendo em vista o tamanho da parcela rural que receberam. Algumas destas áreas não conseguem sustentar dois bovinos adultos ou 20 ovinos ou caprinos adultos. Com esta quantidade de animais, costuma não ser possível a produção de renda anual para suprir minimamente a necessidade familiar. Sendo assim, as famílias precisam recorrer a rendas advindas de programas sociais como Bolsa Família e outros. Logo, a esperança de uma vida melhor no campo tende a ser frustrada se os indivíduos não possuem o recurso necessário para produzirem o suficiente para se alimentar.

Alguns dos motivos que podem levar a maior parcela das famílias assentadas a não estar produzindo nas áreas concedidas podem ser identificados como questões econômicas, sociais, de gestão ou climáticas.

Com relação às questões econômicas, há famílias com baixa capacidade financeira nas quais quem está com pouca capacidade de investimento não possui condições para investir na agricultura. No caso das famílias que possuem alta capacidade financeira, estas não veem na agricultura um meio de contribuir com sua renda, pois possivelmente possuem rendas advindas de atividades não agrícolas.

Em relação às questões sociais, estas possuem um caráter mais amplo e sugestiona uma análise de alguns fatores:

a) A falta de aptidão para trabalhar na agropecuária, uma vez que o ramo agropecuário é composto, em boa parte, de trabalho árduo em meio à insalubridade do campo, como exposição ao sol forte, utilização de ferramentas pesadas, isso tudo demanda sempre muito esforço e traz pouco retorno financeiro;

b) A falta de empregos no meio rural e a dificuldade dessas famílias na inserção do mercado de trabalho urbano - pela inexistência de educação de qualidade disponível a todos - causa uma forte pressão como busca de sua subsistência em áreas de assentamentos;

c) A busca por moradia e não pela terra, similar ao que acontece aos casos anteriores, a falta de oportunidade de trabalho, a baixa renda das famílias, além da criação de famílias com baixa capacidade de sustento, faz com que estas famílias busquem áreas de assentamentos apenas pela existência de moradias, não levando em consideração que elas deveriam cumprir com a função social da terra para que foram beneficiadas.

Outra questão é a falta de senso empreendedor. Muitos desses "agricultores", na realidade, foram "operários rurais", tendo em vista que durante toda a sua vida trabalharam para agricultores ou empresas agrícolas, empregos nos quais havia sempre alguém que lhes dava ordens e pagava pelos seus serviços. Desse modo, ao chegarem nos projetos de assentamentos, estes novos agricultores não possuem juízo empreendedor necessário para buscar produzir sem a existência de um "chefe" para coordenar as atividades. Eles não conseguem tomar atitude ou não possuem conhecimento suficiente para conseguir empreender no trabalho de forma autônoma, não conseguem contabilizar e gerir seus empreendimentos rurais para produzir na agropecuária. 
Por fim e não menos importante, as questões climáticas como um dos aspectos de forte influência para a baixa ou nenhuma produção encontrada na maior parte das famílias beneficiadas. Sem a existência de uma regularidade pluviométrica nos últimos três anos, este fator tem dizimado as criações e plantações no interior do estado assim como na região pesquisada, dificultando a produção, fazendo com que as famílias que se arriscam a plantar ou criar nestas condições acumulem prejuízos quanto ao investimento realizado. Salvo algumas poucas famílias que, apesar de toda a intempérie, ainda conseguem manter um mínimo de produção às custas de muito investimento e trabalho, porém, com pouco retorno financeiro.

Dessa forma, a política pública não pode ser considerada satisfatória, pois a exigência legal define os critérios adequados para um assentamento rural, além de parâmetros técnicos e infraestrutura, diferentes dos que são realmente implementados.

São muitos os desafios da reforma agrária brasileira, pois os recursos são escassos para atender a toda demanda existente nos PA’s e as famílias que ainda não foram ajudadas pela política pública.

É importante haver a compreensão, o questionamento e a avaliação constante das políticas públicas implantadas para que essas possam atender com eficiência, eficácia e afetividade, e assim, poderem alcançar uma maior quantidade de pessoas com menos, economizando recursos que possam ser utilizados em outras políticas ou que possam ampliar o atendimento das já existentes. Por isso mesmo, a sociedade e os executores do PNRA, devem ser mais vigilantes quanto à aplicação de tais recursos, buscando utilizar os conhecimentos produzidos na Nova Gestão Pública como meio de melhorar o uso de todos os recursos e ferramentas atuais em prol de uma sociedade mais justa.

Com relação aos dados levantados, cabe ressaltar que as informações são oriundas de autodeclarações (não comprovadas, passíveis de super ou subdimensionamento). Como a coleta dos dados foi feita apenas através de um formulário com as informações declaradas pelos assentados de cada família, não é possível afirmar que todas as informações sejam precisas, tendo em vista que muitas famílias creem que ao informar as suas rendas reais e que possuem mais do que elas mesmas acham necessário à sua sobrevivência, logo poderiam perder algumas vantagens ou benefícios sociais que recebem.

\section{REFERÊNCIAS}

1. ALVES, Eliseu (Ed.). Migração rural-urbana, agricultura familiar e novas tecnologias. Brasília: Embrapa Informação Tecnológica, 2006. 184 p. Disponível em: < http://biblioteca.ibge.gov.br/ biblioteca-catalogo.html?view=detalhes\&id=265338>. Acesso em: 01 mar. 2016.

2. BRASIL. Decreto $n^{\circ}$ 91.766, de 10 de outubro de 1985. Aprova o plano nacional de reforma agrária - PNRA, e, da outras providências. Disponível em: <http://legis.senado.gov.br/ legislacao/ListaTextoIntegral.action?id=106707\&norma=129768>. Acesso em: 03 jan. 2015.

3. Constituição da República Federativa do Brasil de 1988. Disponível em: <http://www.planalto.gov.br/ccivil_03/constituicao/constituicao.htm>. Acesso em: 19 jan. 2014.

4. . Lei $\mathrm{N}^{\circ}$ 4.504, de 30 de novembro de 1964. Dispõe sobre o Estatuto da Terra, e dá outras providências. Disponível em: <http://www.planalto.gov.br/ccivil_03/leis/L4504.htm>. Acesso em: 26 nov. 2015. 
5. . Lei no 5.868, de 12 de dezembro de 1972. Cria o Sistema Nacional de Cadastro Rural, e dá outras providências. Disponível em: <http://www.planalto.gov.br/ccivil_03/leis/L5868. htm>. Acesso em: 25 set. 2015.

6. . Lei $\mathrm{N}^{\circ}$ 6.746, de 10 de dezembro de 1979. Altera o disposto nos arts. 49 e 50 da Lei no 4.504, de 30 de novembro de 1964 (Estatuto da Terra), e dá outras providências. Disponível em: <http://www.planalto.gov.br/ccivil_03/leis/1970-1979/L6746.htm>. Acesso em: 25 nov. 2015.

7. . Lei $\mathrm{N}^{\circ}$ 8.629, de 25 de fevereiro de 1993. Dispõe sobre a regulamentação dos dispositivos constitucionais relativos à reforma agrária, previstos no Capítulo III, Título VII, da Constituição Federal. Disponível em: <http://www.planalto.gov.br/ccivil_03/leis/L8629.htm>. Acesso em: 17 set. 2015.

8. Plano Nacional de Reforma Agrária (PNRA). 1985. Disponível em: <http:/ / portalantigo.incra.gov.br/index.php/servicos/publicacoes/pnra-plano-nacional-de-reforma-agraria $>$. Acesso em: 10 dez. 2014.

9. CARVALHO, Leandro. Colonização do Brasil. Disponível em: < http://brasilescola.uol. com.br/historiab/colonizacao-brasil.htm>. Acesso em: 26 nov. 2015.

10. FAESC - Federação da Agricultura e Pecuária do Estado de Santa Catarina. Módulo Rural X Módulo Fiscal. Disponível em: <http://www.senar.com.br/portal/faesc/conteudo.php?sec=136>. Acesso em: 26 jan. 2015.

11. FIGUEIREDO, Gislayne Cristina. Experiência e luta pela terra: o assentamento Sepé Tiaraju e o MST. Tese (Doutorado em Psicologia). 397 f. Faculdade de Filosofia, Ciências e Letras - USP. Ribeirão Preto, 2009.

12. FREITAS, Eduardo de. Questão agrária no Brasil. [201-?]. Disponível em: <http:// brasilescola.uol.com.br/brasil/questao-agraria-no-brasil.htm>. Acesso em: 26 nov. 2015.

13. GIL, A. C. Técnicas de pesquisa em economia. 2. ed. São Paulo: Atlas, 1991.

14. INCRA. Instrução Especial/INCRA/n05-A, de 06 de junho de 1973. Dispõe sobre normas, classificações, questionários e tabelas relativas à implantação do Sistema Nacional de Cadastro Rural e a Tributação previstas no Decreto no72.106, de 18 de abril de 1973 e no Decreto 55.891, de 31 de março de 1965. Disponível em: < http:/ /www.incra.gov.br/sites/default/files/uploads/institucionall/ legislacao--/atos-internos/instrucoes/ie5a_060673.pdf>. Acesso em: 30 set. 2015. 
15. Instrução Especial/INCRA/nº 20, de 28 de maio de 1980. Estabelece o módulo fiscal de cada Município, previsto no Decreto n84.685 de 06 de maio de 1980. Disponível em: < http://www.incra.gov.br/institucionall/legislacao--/atos-internos/instrucoes/file/129-instrucaoespecial-n-20-28051980>. Acesso em: 03 set. 2015.

16. Instrução Especial/INCRA No541, de 26 de agosto de 1997. Estabelece o módulo fiscal para os Municípios constantes da tabela anexa. Disponível em: <http://www.incra.gov. $\mathrm{br} /$ sites/default/files/uploads/institucionall/legislacao--/atos-internos/instrucoes/ie51_260897.pdf>. Acesso em: 25 nov. 2015.

17. . Instrução Especial INCRA/no 03, de 11 de abril de 2005. Estabelece o módulo fiscal para os Municípios constantes da tabela anexa. Disponível em: <http://www.incra.gov.br/sites/ default/files/uploads/institucionall/legislacao--/atos-internos/instrucoes/ie03_2005.pdf>. Acesso em: 25 nov. 2015.

18. . Instrução Normativa $N^{\circ} 11$, de 4 de abril de 2003. Estabelece diretrizes para fixação do módulo fiscal de cada Município de que trata o Decreto n. ${ }^{\circ}$ 84.685, de 6 de maio de 1980, bem como os procedimentos para cálculo dos Graus de Utilização da Terra -GUT e de eficiência na exploração GEE, observadas as disposições constantes da Lei n. ${ }^{\circ}$ 8.629, de 25 de fevereiro de 1993. BRASIL, Disponível em: <http://www.incra.gov.br/media/institucional/legislacao/atos_internos/ instrucoes/instrucao_normativa/IN11_040403.pdf>. Acesso em: 17 fev. 2015.

19.

Norma de Execução $N^{\circ}$ 45, de 25 de agosto de 2005. Dispõe sobre procedimentos para seleção de candidatos ao Programa Nacional de Reforma Agrária., Disponível em: <http://www.incra.gov.br/sites/default/files/uploads/institucionall/legislacao--/atos-internos/ normas/ne_45_250805.pdf>. Acesso em: 10 dez. 2015.

20. . Processo de desapropriação no $21630.000587 / 95-54$ : Laudo de vistoria, mapas e demais peças técnicas. Natal: SR-19, 1995.

21. . Processo de desapropriação no 54330.002242/99-75: Laudo de vistoria, mapas e demais peças técnicas. Natal: SR-19, 1999.

22. . Processo de desapropriação nº 54330.001189/00-64: Laudo de vistoria, mapas e demais peças técnicas. Natal: SR-19, 2000a.

23. . Processo de desapropriação no 54330.002325/00-14: Laudo de vistoria, mapas e demais peças técnicas. Natal: SR-19, 2000b.

24. Processo de desapropriação no 54330.001641/2005-91: Laudo de vistoria, mapas e demais peças técnicas. Natal: SR-19, 2005. 
25. INSA - INTITUTO NACIONAL DO SEMIÁRIDO. Sinopse do Censo Demográfico para o Semiárido Brasileiro: extensão territorial. Disponível em: <http://www.insa.gov.br/censosab/ index.php?option=com_content\&view=article\&id=94\&Itemid=93>. Acesso em: 01 nov. 2015.

26. LANDAU, Elena Charlotte; CRUZ, Roberta Kelly da; HIRSCH, André; PIMENTA, Fernando Martins; GUIMARÃES, Daniel Pereira. Variação geográfica do tamanho dos módulos fiscais no Brasil. Sete Lagoas: Embrapa Milho e Sorgo, 2012.

27. LE TOURNEAU, François-Michel; BURSZTYN, Marcel. Assentamentos rurais na Amazônia: contradições entre a política agrária e a política ambiental. Ambiente \& Sociedade, v. XIII, n. 1, p. 111-130, jan.-jun., 2010.

28. MOURAD, Camila Benatti. Efeito da Regulação sobre sistemas agroindustriais de produção de biodiesel. Dissertação (Mestrado em Administração). 230 f. Faculdade de Economia, Administração e Contabilidade da Universidade de São Paulo - USP. São Paulo, 2010.

29. NETO, Sulaiman Miguel. Questão agrária: doutrina, legislação e jurisprudência. Campinas: Bookseller, 1997.

30. RIBEIRO, Darcy. O Povo Brasileiro: a formação e o sentido do Brasil. 2. ed. São Paulo: Companhia das Letras, 1995.

31. SIATER - Sistema Informatizado de Assistência Técnica e Extensão. Disponível em: <http://siater.mda.gov.br/sys/siater/public/listagem/page/6>. Acesso em: 07 jul. 2014.

32. SOUSA, Rainer. Capitanias hereditárias. [201-?]. Disponível em: <http://brasilescola.uol. com.br/historiab/capitanias-hereditarias.htm>. Acesso em: 26 nov. 2015. 